\title{
Study on "Ecological" Media Construction in the Outdoor Advertising
}

\author{
Jin Yin \\ Huanghe Science and Technology College \\ Zhengzhou, China
}

\begin{abstract}
In today's outdoor advertising design, media as a platform of communicating with the audience, plays an important role in the creative expression and effectiveness of outdoor advertising. Regarding current status of outdoor advertising and media, from the perspective of ecology, this paper attempts a specific expatiation and analysis on selection and combination of outdoor media, media economy, media materials and so on and its main purpose is to direct a correct understanding and effective use of outdoor media for the audience and the market a aimed at the status quo of and media, from the selection and combination of outdoor media, and finally to promote the sustainable development of outdoor advertising.
\end{abstract}

Keywords-media; ecologicalization; outdoor advertising; reasonable and effective

\section{INTRODUCTION}

Since 2005, China's advertising market has had a great change: television, newspapers and other traditional media advertising get a slow growth of income, and even a negative growth in some stages, while LCD TV in buildings, mobile media and other new media advertising get a rapid growth of income [1], which had a significant effect on the development of outdoor advertising media. More and more advertisers tend to new media for their outdoor advertising, and hope to enhance advertising effectiveness and purpose through such new media. While the dissemination and effectiveness of advertising information base on the further understanding and research for outdoor media, with the combination of advertising, and only when we make comprehensive consideration of the advertising object and originality, the ideal advertising effectiveness can be achieved. In the face of the role and current status of media in outdoor advertising, we have to make careful analysis and review, to lay a foundation for the sustainable development of outdoor advertising.

Ecology is a subject specialized in study of ecological phenomenon, we pay more attention to the impact of human activities on the ecological environment. Modern ecology is not only a study of the relationship between biology and environment, but also comprehensive discipline to guide human conduct and to direct the development of the human and biosphere (i.e., the nature, resources and environment). Therefore, all human behavior and creation are of ecology, and all problems can be solved from the perspective of ecology. The ecological system of media refer to people and medium and environment depend on each other for existence through the interaction of material exchange, energy flow and information communication in the certain time and space, to form a unified whole of dynamic balance. [2].

\section{EFFECTIVE SELECTION AND COMBINATION OF OUTDOOR MEDIA}

There are many different kinds of media in the outdoor advertising, and they are different from each other but have their own characteristics and advantages. The regular outdoor media, such as large-size outdoor billboards, single column, electronic screen billboard and other billboard-type advertising media, has independent space and is relatively stable, and the government and the relevant laws and regulations both define the requirements and standards for such media. While all kinds of new media, such as LED, LCD display screen, is produced by high-tech means, which not only quickly improves the novelty and expressive force of outdoor advertising, but also creates many interactive ways to attract the audience for attention and participation, to make the cross-space and cross-time integration possible [3]. Based on this, we can see that the media in the design of outdoor advertising has a wide choice space, and if it is allowed by the relevant departments and meets the overall coordination of landscape, any visual object in outdoor environments can be used as the media of outdoor advertising. The media itself is not good or bad, but its reasonable application and its functions maximization is the key.

The effective selection and combination of media is the important factor to guarantee the ecological development of media and the sustainable development of outdoor advertising. Facing the different objects, environments and creative idea, we can make a combination of advantages for different medias according to the acceptable audience's life and work trace and the effective concentration of urban construction modality etc., so as to support the ecology and effectiveness of information transmission, and to provide the audience with a more pleasant and comfortable display and spread environment. For the choice and discovery of medium, we first should make sure it has some connection with the outdoor advertising, in form, function or content etc. we should follow its differences, advocate diversity, make 
mutual combination and overall optimization, and ensure timely communication and instantaneous availability of information; we should pay attention to the development and use of media, combine with the powerful and unconstrained style of creative imagination and its uncertainty to discover some objects that are not regarded as media in the general concepts, and make creative application to better reflect the uniqueness of advertising originality, attracting attention of the audience and enlarging the effect of advertising communication.

\section{REASONABLE DEVELOPMENT AND EFFECTIVE APPLICATION OF NEW TECHNOLOGY}

The development of modern outdoor advertising changes constantly with the development of media, while the development of media inevitably changes due to the development of science and technology. Therefore, every major development and change of technology means that advertising technology and advertising form will have a qualitative leap. Human aesthetic and preferences also change in the change of science and technology and materials. With the help of the power of science and technology, today's outdoor advertising design has surpassed traditional forms of outdoor advertising. The introduction of innovative technology such as digital media technology, interactive technology, and virtual art changes the process that outdoor advertising shows the effect and the communication environment, makes people are not simple information receiver any more, but can participate in the design of outdoor advertising, even have to get involved to ensure the integrity of outdoor advertising. So to speak, the "four news" of outdoor advertising of new media, new technology, new equipment and new materials inject vitality for modern outdoor advertising and start a new era of outdoor advertising.

We pursue media ecology is to maintain the stability of the whole media environment, thus build a stable and harmonious living environment for modern outdoor advertising. In the face of stage with flourishing China's modern media form, we should pay attention to: innovative technology is applied to media, which change the face of media as well as the presentation state of outdoor advertising. But technology after all is only a means and the technical reformation and innovation is ever-accelerated and media is just an advertisement information carrier. Although they can have an effect on outdoor advertising, the development of outdoor advertising and the harmonious coexistence of human-environment cannot be decided only by technology.

Facing these innovative technology presented by media development in today's outdoor advertising, at first, we should understand the advantages and disadvantages, select and apply based on our own ability and principal part of design, the characteristics and personality of the object, etc.; at the same time, the application of media and new technology and new materials must closely integrates creative ideas of advertising, develops the possibility of new media in originality, cooperates with originality to effectively use technology, or looks for environment and means which can better convey information in technology to ensure the embodiment of the maximum value of the existence and development of media new technology.

\section{THE Moderate Performance OF Media ECONOMY}

In outdoor advertising design, when we mention media, we must talk about money. Because if we regard the whole information dissemination activity as advertising design, and the most valuable and the most expensive in design is media. The so-called promotion of ecology itself emphasizes the objection to waste and pollution.

In the process of the development of outdoor advertising, because of its advantages such as low price, high reaching rate and long release time, it is highly appreciated by business owners all the time. Therefore, many entrepreneurs in China in the process of image promotion and brands establishment, they all will select it to spread information. According to the research data nearly three years shows: over the years, nearly forty percent of advertisers in China agree that "outdoor media will become important carriers in advertising and marketing activities" [1]. In November, 2011, 25 outdoor billboards in Xi'an city should sale 46.6 million Yuan by auction through competitive bidding, which is the first time when the amount of outdoor advertising auction has been the largest since 2003 in Xi'an city. While an advertising board located in Xinjiamiao interchange of north second ring in Xi'an should sale fancy price of 5,700 thousand yuan. This price is the highest in media cost of the whole China outdoor advertising. From this phenomenon, first of all, we can see that people's attention for outdoor advertising and the important role it plays in the whole information dissemination activities. Therefore, we must conform to the situation, cut in integrally, research and study all the components of outdoor advertising and its relationships between human, society and environment to ensure the sustainable development of outdoor advertising. But meanwhile, we should also reflect: whether "the expensive is the good" really can reach the optimization of effect? Whether once the famous "decline of bid winner Qin Chi in win industry" embodies the principle that the advertising "can support a ship also upset it" or not? In the future development of outdoor advertising, if bear the cognition shackles of "high media cost" and that "the expensive is the good", the economy will inevitably trigger the vicious spiral and abnormal development of outdoor advertising then affect the stability of whole ecosystem of outdoor advertising in China.

Besides, our country's existing relevant management and system for outdoor advertising design and delivery are lack of standardization and it presents dynamic and instability in its development. Therefore, although the advertising media is acquired through legal means in earlier stage, it will probably be torn down in a certain time or a certain stage. According to incomplete statistics, in earlier stage of Beijing 2008 Olympic Games, the legal advertising boards torn down in Beijing has reached tens of thousands of pieces, which result in a huge waste of money.

Outdoor media is just a delivery tool and carrier for advertisers to release information, a link and element to 
create economic. The difference and change of itself have effect on the design and effect of outdoor advertising, but communication means itself cannot represent communication effect, "the expensive is not always the good". As outdoor advertisers or outdoor advertisement producers, we should recreate and reuse through rational utilization, valid combination and exerting intelligence and wisdom, instead of using the height of media cost to measure the effect. We should correctly guide the economic factors of media through effective utilization and combination rather than getting valuable media only through competition and comparison. Meanwhile, as local governments and relevant administrative departments, they also should adjust measures to local conditions to develop a practical and feasible standardizing system to distribute reasonably and guide effectively, which is the primary task to solve the problem of outdoor media at present.

\section{The ECOlOGical Protection of TECHNICAL MATERIALS OF MEDIA}

In outdoor advertising design, medium is a carrier to convey advertising information and material is the specific presentation of different media. It also involves in the ecological protection of media materials to establish ecology of media, which is an inevitable element to maintain our ecological stability of natural environment.

Due to its own strengths and characteristics of outdoor advertising design, the development and discussion of outdoor advertising materials have attracted attention not as good as that of packaging design, architectural design and interior design for quite a long time. However, with the generation of new media and the gradual enhancement of design communication, receivers could see an increasing number of materials in different media. For single traditional media, we usually use spray painting technology in waiting rooms, road signs and so on and we mostly use flex banner, fiberglass mesh, car sticker and etc. We mostly use PC board, PVC foam board, acrylic sheet, aluminum and etc. in outdoor advertising structure design, and UV glue, glass cement and etc. in the combination of materials. After the involvement of special forms and electronic technologies, a large number of flash cloths, film and electron emitters are widely used in design. These materials are scattered in the surrounding of our lives along with outdoor advertising. Currently, businessmen only care about benefits and receivers blindly pursue the experience of innovation. Most of us gradually ignore to concern outdoor advertising materials, so that a lot of contaminated garbage is scattered in our surroundings.

Ecology and Ecological Design give us a wake-up call. First, it requires us to choose eco-friendly decorative materials for outdoor media which do not cause harm to human body and natural environment and can be used as a renewable resource.

Secondly, it encourages us to use eco-design technologies. By using eco-technology and eco-design, and taking advantage of nature, it can increase people's demand. In other word, it can create harmony among human beings by using fine weather and favorable geographical position. For example, in tradition, we produce light with the aid of coal for the supply of neon light and liquid crystal display and other outdoor advertising in new technologies. But now we can change acquisition channels of light by the effective use of solar energy, luminous energy, or even natural light and so on.

Third, it requires us to save energy and extensively use clean energy to coordinate research and development of new energies. People should develop saving awareness. Specifically, we could use inherent natural resources and environmental resources and media resources through creative ideas to reduce energy costs in design. For example, we could use road as medium for the creation of outdoor advertising, which is creative but also can reduce environment pollution and destruction caused by the release of media.

Fourth, it requires us to focus on modern advanced technologies, efficiently use high technologies to reduce costs, save energy consumption, and promote the innovation and development of outdoor advertising design.

Finally, we should also strengthen ecological education for receivers in order to reach the goal of using ecological media materials. We could advocate it by the use of outdoor advertising in order to improve ecological awareness of people, including advertisers and receivers. In additions, relevant departments should strengthen their management and supervision. Advertising producers should improve their self-awareness and strengthen the spirit of innovation. Consequently, we could ensure the sustainable development of outdoor advertising.

\section{CONCLUSION}

In contemporary outdoor advertising design, designers should correctly understand the role and value of the media, and should be able to guide outdoor advertising media design with the application of theories of ecology to effectively enhance the efficiency and role of media, and ultimately to promote sustainable development of outdoor advertising.

\section{REFERENCES}

[1] Du Guoqing and Shao Huadong. Research Report on Development Trend of Outdoor Media in China - Best Practices on Outdoor Marketing. Beijing: Social Sciences Academic Press, 2008.

[2] Shao Peiren. Media Ecology - Research of Media as Green Ecology. Beijing: Communication University of China Press, 2008.

[3] Wei Ying. Innovation Research of Outdoor Advertising Media Language. 2011, 32(2:)1-4.

[4] Wang Kaihong and Guan Xuelun. Non-mainstream Outdoor Advertising Design. Harbin: Heilongjiang University Press, 2010. 